\title{
Investigation of Cutting Performance of a Circular Saw Blade Based on ANSYS/LS-DYNA
}

\author{
Zhiwen Wang1 - Qingliang Zeng1,3* - Zhenguo Lu² - Lirong Wan ${ }^{1}-$ Xin Zhang1 - Zhihai Liu ${ }^{2}$ \\ ${ }^{1}$ Shandong University of Science and Technology, College of Mechanical and Electronic Engineering, China \\ ${ }^{2}$ Shandong University of Science and Technology, College of Transportation, China \\ ${ }^{3}$ Shandong Normal University, College of Information Science and Engineering, China
}

The circular saw blade is widely applied in rock processing; its cutting performance significantly impacts rock processing. Therefore, the numerical simulation model of rock cutting with the flexible circular saw blade has been established to investigate the effects of cutting parameters on the stress and cutting force of circular saw blade, and the damage and stress of rock in the circular saw blade cutting into rock vertically at constant feed speed and rotation speed. The research results indicate that the stress of the saw blade and rock rises with the increase of feed speed and rotation speed of the saw blade. Furthermore, the rock damage and the cutting force of the circular saw blade increase with the increasing feed speed and decrease with increasing rotation speed. The circular saw blade cutting force, vertical force, and horizontal force increase with the rising distance between the double circular saw blade. However, the axial force decreases. The research results of cutting hard rock with the flexible circular saw blade can aid in the optimization of cutting parameters and improve cutting efficiency.

Keywords: circular saw blade, rock damage, cutting force, stress

\section{Highlights}

- $\quad$ The circular saw blade cutting rock numerical simulation is established based on ANSYS/LS-DYNA.

- $\quad$ The numerical simulation and uniaxial compression test results are compared to verify the numerical simulation model and improve the accuracy.

- $\quad$ The influence of the circular saw blade cutting parameters on cutting performance has been studied.

- $\quad$ The results indicate that the stress of the saw blade and rock rises with the increasing feed speed and rotation speed.

\section{INTRODUCTION}

The circular saw blade has good cutting performance and is widely used for ceramics, marble, glass, and other materials with high hardness and brittleness. Many scholars have researched the circular saw blade and studied the influence of structural parameters, cutting parameters, and rock properties on the specific cutting energy consumption, wear of saw blade, and cutting force, and explored the circular saw blade noise through modal analysis.

Many scholars have researched the cutting force, and the specific energy consumption of circular saw blades and the effect of cutting parameters and rock properties on the circular saw blade cutting performance. Aydin et al. [1] to [3] studied the effect of the operating parameters and the rock properties on energy consumption with the experiments. Goktan et al. [4] studied the effect of Knoop micro-hardness on the sawblade specific cutting energy. Li et al. [5] researched the tool wear effect on cutting energy. Yilmaz et al. [6] investigated the material remove rate influence on specific cutting energy. Ataei et al. [7] applied the sawability index to evaluate the rocksawing energy consumption. Atici et al. [8] studied the prediction model of the cutting specific energy and the drilling with the regression analysis method. Aslantas et al. [9] researched the axial force influence on cutting performance. Ersoy et al. [10] investigated the cutting parameters effect on cutting performance. Tumac et al. [11] and [12] studied the rock properties influence on the saw blade cutting performance. Mikaeil et al. [13] researched the rock physical and mechanical properties for optimizing machine application. Yilmaz et al. [14] studied the active power consumption, force ratio, specific wear rate, and noise emission of the sandwich core saw blade and traditional saw blade. Tonshoff et al. [15] studied the mechanism of the interaction between diamond particles and rock. $\mathrm{Xu}$ et al. [16] investigated the influence of cutting speed, cutting depth, and feed rate on cutting force. Karakurt et al. [17] studied the cutting force of the saw blade on granite in cutting granite. Buyuksagis and Goktan [18] established the empirical equation of specific cutting energy consumption of different natural stones based on the diamond saw blade cutting experiment. Jiang et al. [19] came up with a new gangue distribution function to simulate the gangue distribution condition and studied the cutting force and specific cutting energy with different gangue. Agarwal and Rao [20] 
discussed the mechanism of damage and material removal of $\mathrm{SiC}$ cutting. Burek et al. [21] analysed the cutting edge-shape cutting-force components model, and the study proved that serrated cutting edges adopting end mills had lower cutting force components.

$\mathrm{Lu}$ et al. [22] explored rock-cutting performance with a cutting saw blade with numerical simulation and experimental methods. Zeng et al. [23] studied the distance between the sawblade and free surface influence on rock cutting performance. Hoang et al. [24] researched the milling conditions effect on surface roughness with the test and analyzed the cutting conditions impact on cutting force and the surface amplitude. Liu et al. [25] have studied the milling cutting wear and geometric structure parameters on the machined surface integrity and cutting force.

Fermando et al. [26] established the mathematical cutting force prediction model of rotary ultrasonic cutting rock, and predicted the relationship between input variables and cutting force. Zuperl et al. [27] presented a neuro-mechanistic model to accurately predict the multidirectional layer material helical end milling cutting force. Peng and Fang [28] proposed a resultant force-positioning model based on the tangential force distribution on the saw blade, which was verified with experiments. Liu et al. [29] studied the rock damage on rock fracture and cutting performance with the discrete element method.

Many scholars have researched the saw blade and rock fracture mechanism; however, there is less investigation on circular sawblade cutting rock as a flexible body based on numerical simulation of the rock cutting process. Furthermore, in the circular saw blade cutting rock process in the numerical simulation model, the rock breaking effect is ideal. The influence of lubrication during circular saw blade cutting is not considered. The hard rock cutting studied in the paper is represented by the granite, which will be extended to other hard rocks in the following research. The cutting parameters of the flexible circular saw blade influence on rock damage and rock stress and circular saw blade stress and the cutting force is investigated with the ANSYS/LS-DYNA to establish the flexible circular saw blade cutting rock numerical simulation model. The circular saw blade feed speeds are set as $0.10 \mathrm{~m} / \mathrm{s}$, $0.15 \mathrm{~m} / \mathrm{s}, 0.20 \mathrm{~m} / \mathrm{s}, 0.25 \mathrm{~m} / \mathrm{s}$, and $0.30 \mathrm{~m} / \mathrm{s}$, and the rotation speeds are defined as $1000 \mathrm{r} / \mathrm{min}, 1500 \mathrm{r} / \mathrm{min}$, $2000 \mathrm{r} / \mathrm{min}, 2500 \mathrm{r} / \mathrm{min}$, and $3000 \mathrm{r} / \mathrm{min}$. To optimize the circular saw blade cutting parameters and improve cutting efficiency, the effects of saw blade feed speed, rotation speed, and other parameters on the circular saw blade stress and cutting force explored the effect of rock damage and breakage.

\section{THE MODEL OF ROCK DAMAGE}

The inhomogeneous propagation of cracks causes the anisotropy of derived materials. The anisotropic behaviour needs to be considered to establish the constitutive damage relation with the action of external load. Consider the normal vector discreteness, and each crack family is given a damage variable to describe the crack state. The damage variables of all fracture families are defined as a set, expressed as Eq. (1), $d_{i}$ is the internal damage variable of the $i^{\text {th }}$ crack.

$$
D=\left\{d_{1}, d_{2}, \ldots, d_{N}\right\} .
$$

To simplify the equation, it should first be considered that the rock matrix contains a single group of fractures. In general, assuming that the normal vector of the group fractures is $\mathbf{n}$, and the $d=d(\mathbf{n})$, used to represent the fracture distribution density, that is, the damage variable. It is necessary to determine the free energy expression of the fracture matrix system to establish a damage mechanics model based on thermodynamics. When only the energy dissipation caused by crack propagation is considered, the strain-free energy of the system is the function of the macroscopic variable $\varepsilon$ and the damage variable $d$, as plotted in Eq. (2):

$$
\psi(\varepsilon, d)=\frac{1}{2} \varepsilon: C^{\mathrm{hom}}(d): \varepsilon,
$$

among that, $C^{\text {hom }}(d)$ is the effective elastic tensor of the damaged material.

The state variable, called thermodynamics associated with internal variables, is the energy dissipation's driving force, which can be obtained by deriving the free energy from the internal variables. First, establish the macro stress-strain relation as shown in Eq. (3).

$$
\sigma=\frac{\partial \psi}{\partial d}=C^{\text {hom }}: \varepsilon
$$

The thermal force related to the damage variable is obtained, that is, the damage drive force.

$$
F_{d}=-\frac{\partial \psi}{\partial d}=-\frac{1}{2} \varepsilon: \frac{\partial C^{\mathrm{hom}}}{\partial d}: \varepsilon .
$$

The combination of micromechanics and thermodynamics based on macroscopic expression is an effective method of damaging fractured materials. On the one hand, the effective mechanical 
properties of the materials are determined by means of micromechanics and the constitutive equation and internal variable evolution criterion are established by fully considering the mechanical mechanism of material damage and failure. On the other hand, based on the irreversible thermodynamics theory of internal variables, the thermodynamic constraints of the constitutive equation and the development process of the standardized numerical program are provided, which can consider the engineering practicability of the constitutive model. According to the second law of thermodynamics, the energy dissipation caused by fracture propagation is nonnegative, and it satisfies Eq. (5).

$$
D_{e}=F_{d} \dot{d} .
$$

In the framework of the thermodynamics, the damage criterion based on the strain energy release rate is usually adopted, shown as Eq. (6)

$$
g\left(F_{d}, d\right)=F_{d}-R(d) \leq 0,
$$

where $R(d)$ is the resistance function of damage evolution (crack propagation), shown in the damage criterion Eq. (7). The loading conditions are as follow:

$$
\left\{\begin{array}{ll}
\dot{d}=0 & F_{d}<R(d) \\
\dot{d}>0 & F_{d} \geq R(d)
\end{array} .\right.
$$

In the analysis of meso-damage mechanics, the need for analytical mathematical expression is considered, and it is usually assumed that the fracture propagation process is similar, meaning that the fracture shape remains coin-shaped and only propagates in the damage injuring plane, so the normal vector of fracture surface does not change.

Assuming that the rock is orthorhombic material, the damage evolution obeys the orthogonalization criterion Eq. (8).

$$
\dot{d}=\lambda^{d} \frac{\partial\left(F_{d}, d\right)}{\partial F_{d}}, \quad \lambda^{d} \geq 0,
$$

where, $\lambda^{d}$ is the damage multiplier.

Similar to the classical plastic theory, the damage evolution equation considering the loading and unloading condition is Eq. (9).

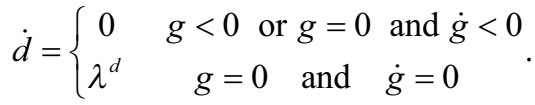

The damage multiplier $\lambda^{d}$ can be determined by the damage consistency condition $(g=0$ and $\dot{g}=0)$, as the following Eq. (10).

$$
\dot{g}=\frac{\partial g}{\partial \varepsilon}: \dot{\varepsilon}+\frac{\partial g}{\partial d} \dot{d} .
$$

In addition, the stress-strain relationship in the form of rate can be established based on the damage evolution criterion. Firstly, the macroscopic stressstrain relationship is expressed in differential form as the Eq. (11):

$$
\dot{\sigma}=\dot{C}^{\text {hom }}: \varepsilon+C^{\text {hom }}: \dot{\varepsilon} .
$$

Furthermore, there is the following equation, shown as Eq. (12).

$$
C^{\mathrm{hom}}: \varepsilon=\frac{\partial C^{\mathrm{hom}}: \varepsilon}{\partial d} ; \dot{d}=-\frac{\partial F_{d}}{\partial \varepsilon} \lambda^{d}=-\frac{\partial g}{\partial \varepsilon} \lambda^{d},
$$

and then obtain Eq. (13).

$$
\dot{\sigma}=C^{\mathrm{tan}}: \dot{\varepsilon},
$$

where, $C^{\text {tan }}$ is the tangential elastic tensor of the material, the specific expression as Eq. (14).

$$
C^{\mathrm{tan}}=C^{\mathrm{hom}}-\frac{1}{H_{d}} \frac{\partial g}{\partial \varepsilon} \otimes \frac{\partial g}{\partial \varepsilon},
$$

among them, the damage hardening parameters $H_{d}=\partial g / \partial d$.

\section{NUMERICAL SIMULATION MODEL}

The research flow chart of the circular saw blade cutting rock with various feed speeds and vertical feed is shown in Fig. 1.

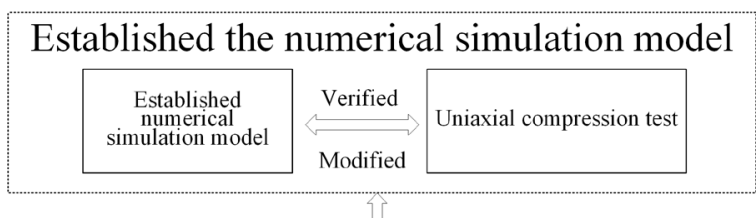

The circular saw blade cutting rock process
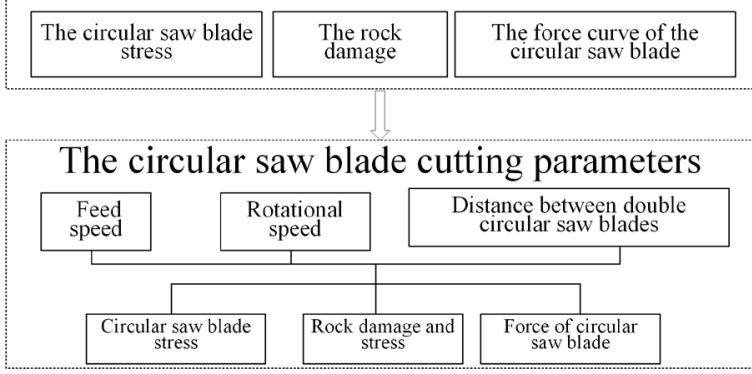

Fig. 1. The circular saw blade cutting rock research flow chart

The numerical simulation model is established, and the feasibility of the model is verified using the 
uniaxial compression experiment and the numerical simulation with the same parameters. The circular saw the changes in the circular saw blade stress, rock damage, cutting force, vertical force, horizontal force, and the axial force curves with the cutting distance at the second step. The feed speed, rotational speed, and the distance between the double circular saw blades affect the circular saw blade stress and forces, and the rock damage and the stress have been researched in the third step.

\subsection{Established Numerical Simulation Model}

Establish the circular saw blade cutting a rock geometric model by SolidWorks. The cuboid size is $500 \mathrm{~mm} \times 200 \mathrm{~mm} \times 200 \mathrm{~mm}$; the circular saw blade diameter is $390 \mathrm{~mm}$, and there are 24 segments. Import the geometric model into the ANSYS/LSDYNA to establish a circular saw blade cutting rock numerical simulation model. Applied the MeshTool to mesh the model with the SOLID164, a hexahedral element with eight nodes, to mesh the rock and circular saw blade. Define the circular saw blade material as PLASTIC_KINEMATIC, and the rock material is defined as RHT; the fundamental rock properties parameters are shown in Table 1. The contact between rock and the circular saw blade is set as SURFACE TO SURFACE_ERODING. Add constraints, the full displacement constraints and rotation constraints are added to the bottom surface of the rock, add $X, Y$ direction displacement constraints to the front and back surface of the rock, and add $X$, $Z$ direction constraints to the left and right surfaces of rock. Apply the Z-direction displacement constraint and rotation constraint around $X$ and $Y$-axes to the circular saw blade, which is plotted as Fig. 2. To improve the accuracy of numerical simulation, add the no-boundary-reflection condition to the un-cut surface of the rock model to simulate the large rock mass with a small model. Apply the initial rotation around the $Z$-axis clockwise and the initial feed speed along the $X$-axis to the flexible circular saw blade model. The motion load of the circular saw blade is set to rotate around the $X$-axis clockwise and feed along the $X$-axis. The solution time and calculation step are defined as 1 and $0.02 \mathrm{~s}$, respectively. The established numerical simulation model is exported to generate the $\mathrm{k}$ file and apply the ANSYS solver to solve the $\mathrm{k}$ file. The workstation is used to solve the numerical simulation model, and the calculation core is set to 40 calculation cores.
Table 1. The rock key properties parameters

\begin{tabular}{lc}
\hline Elastic modulus [GPa] & 57.2 \\
\hline Density $\left[\mathrm{kg} / \mathrm{m}^{3}\right]$ & 2670 \\
\hline Compressive strength [MPa] & 120 \\
\hline Tensile strength [MPa] & 11.8 \\
\hline Poisson's ratio & 0.20 \\
\hline
\end{tabular}

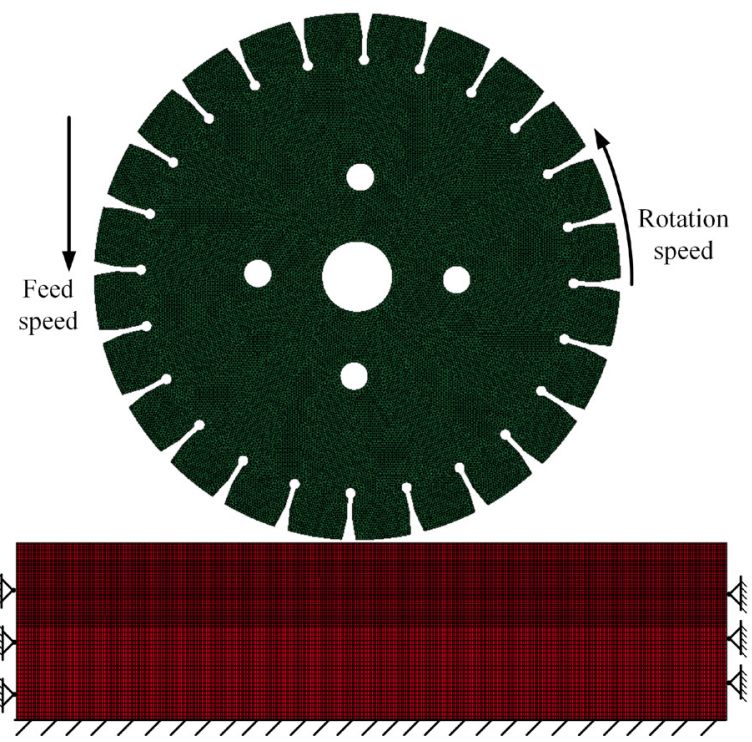

Fig. 2. The circular saw blades cutting rock numerical simulation model

\subsection{Verified and Modification}

The numerical simulation and uniaxial compression test results are compared to verify the numerical simulation model and improve the accuracy. Two $70 \mathrm{~mm} \times 70 \mathrm{~mm} \times 10 \mathrm{~mm}$ cylinders are built as the base and the loading body, and a $\Phi 50 \mathrm{~mm} \times 100 \mathrm{~mm}$ cylinder is applied to simulate the rock column. Set the base and loading body as rigid, set the rock column as RHT material, and add the total constraints to the bases. The contact type between the rock column and the base and between the rock column and loading body is set as the surface-to-surface erosion contact. The loading body is added with $0.001 \mathrm{~m} / \mathrm{s}$ uniform motion along the cylinder's axis, as shown in Fig. 3a. The uniaxial compression test is carried out on the granite core sample on the uniaxial compression test bench, and the stress-strain curve is measured. The experiment results are shown in Figs. $3 b$ and $\mathrm{d}$, marking the rock sample cracks. The uniaxial compression's numerical simulation results are shown in Figs. $3 \mathrm{c}$ and d. The rock cracks are consistent with the uniaxial compression numerical simulation results and test results. The stress-strain curves of the test and 
numerical simulation are shown in Fig. 3d. The peak stress of the numerical simulation is $108.13 \mathrm{MPa}$, and the peak stress of the test result is $108.55 \mathrm{MPa}$. The stress error between the numerical simulation and test results is $0.39 \%$, which means that the numerical simulation model is accurate and reliable.

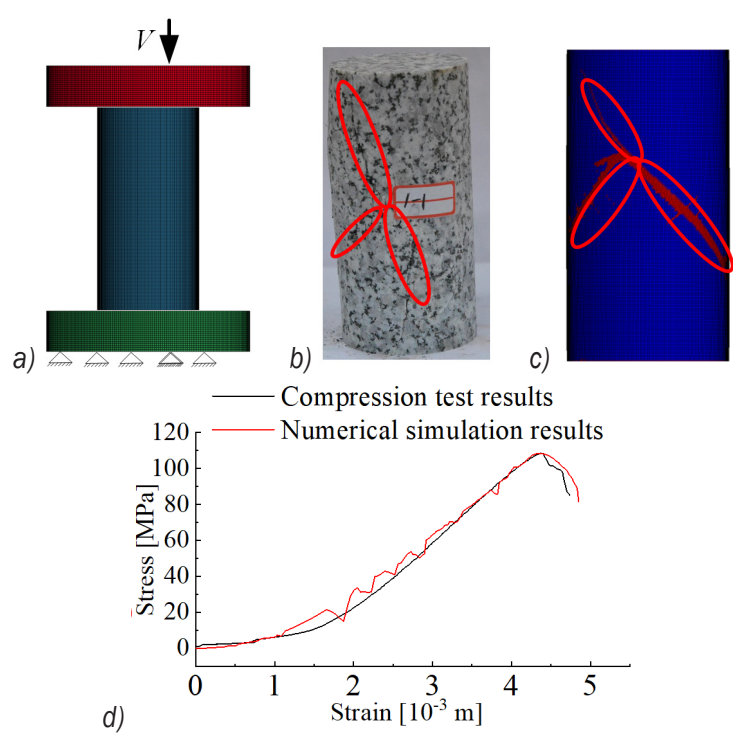

Fig. 3. The results of uniaxial compression; a) the numerical simulation of the uniaxial compression, b) the result of the uniaxial compression test, c) the result of the uniaxial compression numerical simulation, and d) the stress-strain curve of the numerical simulation and test

\section{RESULTS AND DISCUSSION}

\subsection{The Circular Saw Blade Cutting into Rock Process}

The circular saw blade cutting rock with a rotation speed of $2000 \mathrm{r} / \mathrm{min}$, feed speed of $0.30 \mathrm{~m} / \mathrm{min}$ cutting into rock vertically is shown in Figs. 4, 5, and 6 . When the circular saw blade does not contact the rock, the circular saw blade's middle deformation is obvious, and the stress nephogram extends to the direction of the four holes, as shown in Fig. 4a. With the action of the driving force, the circular saw blade matrix strain extends outward along the rotation direction, as plotted in Fig. 4b. In addition, the stress area distribution appears at the bottom of the circular saw blade and the groove of the saw blade matrix in contact with the rock. Stress also occurs in the rock where the circular saw blade contacts it, as shown in Fig. 5a. The stress concentration point appears in the rock that is in contract with the saw blade and expands rapidly under the cutting action of the saw blade, as shown in Fig. 5b. After the saw blade stably cuts the rock, the stress range and peak value in the central area of the saw blade decrease obviously, as shown in Fig. 4c. While the circular saw blade continues to cut into the rock, the circular saw blade segment stress increases obviously. The stress of saw blade segments appears from the saw blade's position in contacting the rock. When the saw blade extends the distance backward along the rotation direction, the stress of the saw blade gradually decreases until it disappears. With the increased circular saw blade cutting depth, the circular saw blade's contact arc length and the rock increase. Moreover, the saw blade segments ${ }^{6}$ stress decreases and appears to need more time while the saw blade cutting out of contact with the rock, and the stress range of the circular saw blade increases significantly.

When the circular saw blade starts running, the stress appears in the saw blade matrix under the action of the large driving force, and the stress gradually decreases in a ring shape from the centre to the outside. When the circular saw blade segment contacts the rock, the stress of the saw blade matrix increases significantly, and the arc extension appears at the outer edge of the stress, as shown in Fig. 4. The rock stress begins to appear when the rock cutting with the circular saw blade, and rock stress appears due to extrusion. Under the rotary shear of the circular saw blade, the rock stress extends along the rotation direction. Moreover, the stress range at the position where the rock contacts the saw blade is smaller than when the saw blade is separated from the rock. While the circular saw blade cuts into rock stably, the circular saw blade matrix stress area and peak value decrease, and the stress cloud area is concentrated. Meanwhile, while the circular saw blade cuts the rock, the rock stress area is mainly distributed along the cutting arc of the circular saw blade. The stress nephogram of the rock in the feed direction of the saw blade is an extensive cutting-away position of the saw blade. Due to the rock fragments on both sides of the sawed joint and the circular saw blade squeezing each other on the rock wall of the saw joint, there is apparent stress appearing on the rock wall. Some rock units do not restore the plastic strain of rock with the removal of the loading, with the shear and tension of the saw blade cause the plastic strain.

In the rock-cutting process with a circular saw blade, when the circular saw blade contacts the rock, the stress concentration point appears on the rock due to the circular saw blade cutting the rock with high cutting speed. The circular saw blade cuts the rock for a certain distance: the contact area between the rock and circular saw blade. For the circular saw blade cutting for a certain distance, at the contact area 

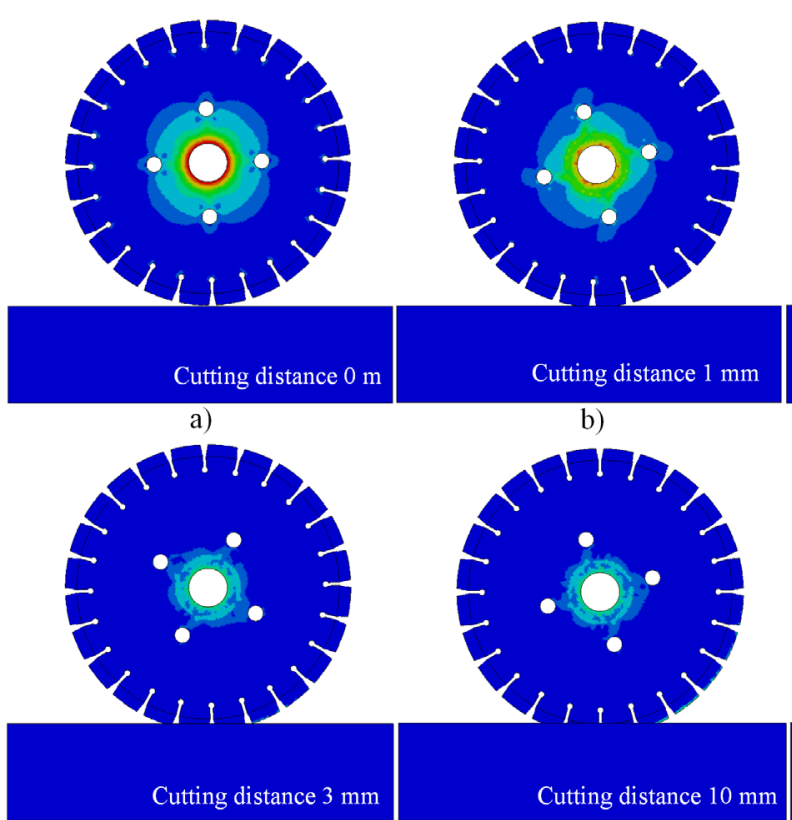

d) b)

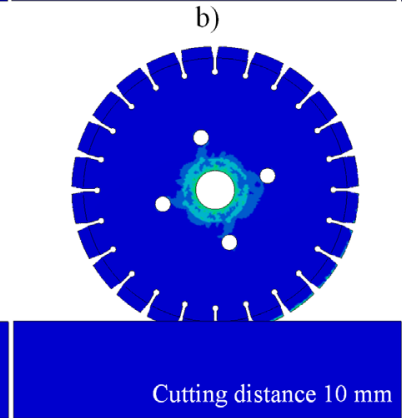

e)

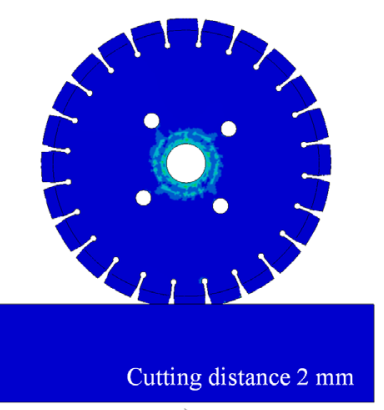

c)

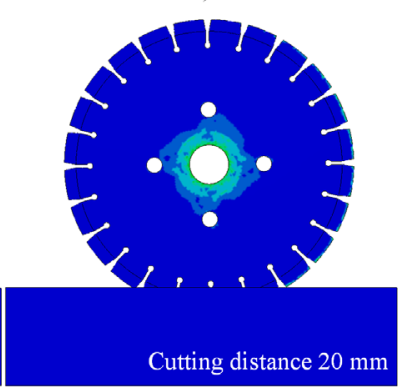

f)

Fig. 4. The circular saw blade stress nephogram of the circular saw blade cutting rock process

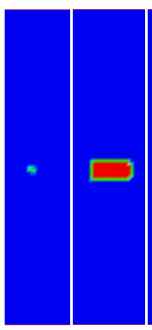

a)

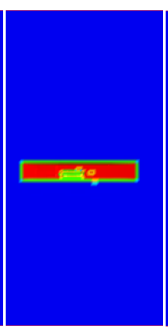

c)

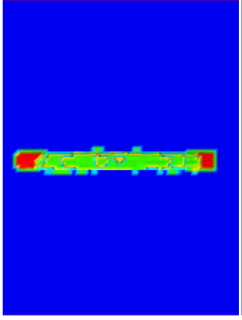

d)

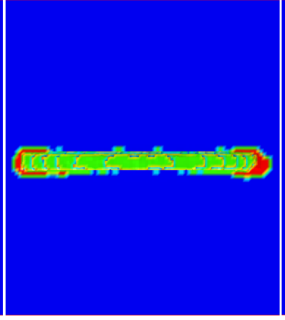

e)

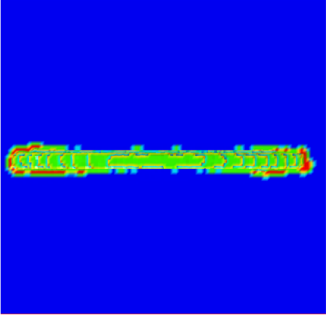

f)

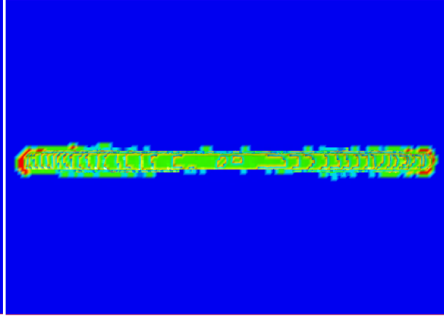

g)

Fig. 5. The rock damage nephogram of a circular saw blade cutting rock

between the circular saw blade and rock, a prominent stress area appears and expands. When the cutting depth reaches $0.005 \mathrm{~m}$, the damage value of the rock unit reaches 1 under the action of the circular saw blade. While the circular saw blade continues to cut the rock, the forms a rock saw gap of a certain width and rock walls on both sides of the circular saw blade. The circular saw blade continues to cut the rock, the rock forms a certain saw gap, and the rock walls on both sides of the circular saw blade is randomly broken. When the cutting depth of the circular saw blade is $0.015 \mathrm{~m}$, the damage area at both ends of the saw seam is prominent, but the damage value at both sides of the saw seam is smaller, and the middle section width of the saw seam is slightly narrower than that at both ends.

Moreover, while the circular saw blade cutting depth reaches $0.020 \mathrm{~m}$, the damaged area at both ends of the saw seam decreases significantly. It is significantly narrower than the middle section at both ends of the saw seam. With the increasing cutting depth, the damage area at both ends of the saw seam decreases significantly.

The cutting force curves of a circular saw blade cutting rock are shown in Fig. 6. While the circular saw blade contacts the rock, the circular saw blade cuts into the rock vertically at the constant cutting speed and feed speed. The cutting force and vertical force increase sharply with the impact between the circular saw blade and rock. The cutting force and vertical force fluctuate up and down around the stable value, closely related to the cutting depth of the circular saw blade. The cutting force, horizontal force, and vertical force increase with the increase of cutting depth. When the circular saw blade cuts into the rock, the axial force of the saw blade is small. With the increasing cutting depth, the axial force amplitude curve of the saw blade, the contact arc length between 


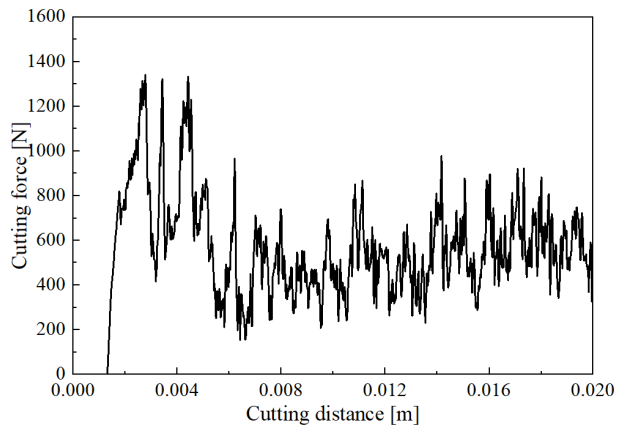

a)

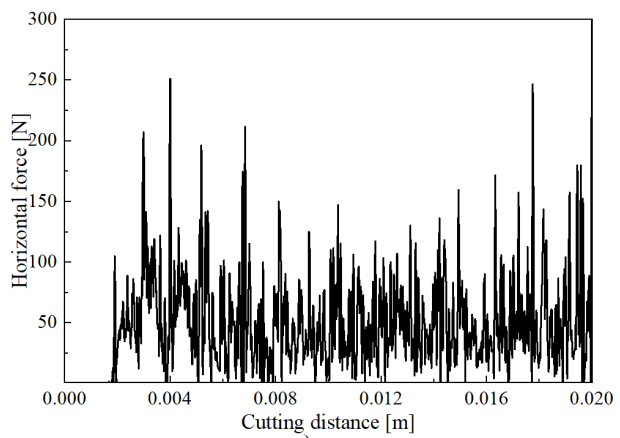

c)

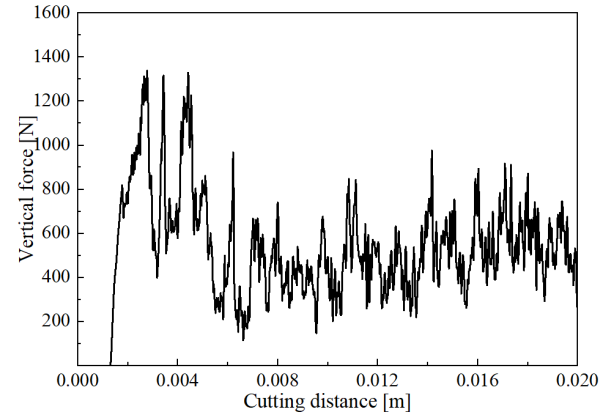

b)

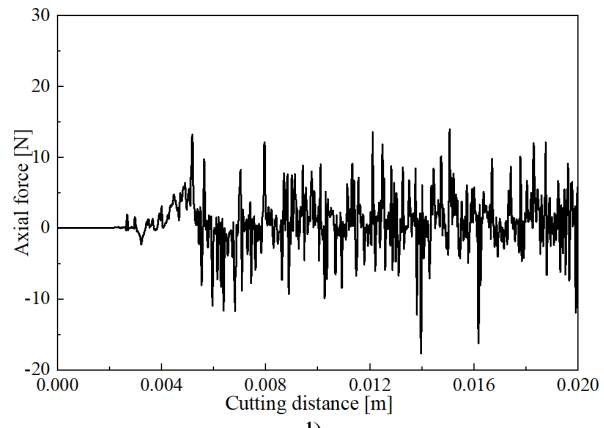

d)

Fig. 6. The force curve of the circular saw blade cutting rock; a) cutting force curve, b) vertical force curve, c) horizontal force curve, d) axial force curve

the saw blade and rock increases, and the cutting force and vertical force increase. Meanwhile, the overlap area between the circular saw blade and rock increase with the increasing cutting depth. The discharge speed of rock debris, which is formed by the circular saw blade cutting rock, slows down, and the axial force amplitude increases owing to compression of the circular saw blade what the rock wall at saw seam both sides.

\subsection{The Influence of Feed Speed on Circular Saw Blade Cutting Performance}

The circular saw blade cuts into rock vertically with a rotation speed of $2000 \mathrm{r} / \mathrm{min}$, and feed speed of $0.10 \mathrm{~m} / \mathrm{s}, 0.15 \mathrm{~m} / \mathrm{s}, 0.20 \mathrm{~m} / \mathrm{s}, 0.25 \mathrm{~m} / \mathrm{s}$, and 0.30 $\mathrm{m} / \mathrm{s}$. The results of the circular saw cutting rock are shown in Fig. 7. In order to investigate the relation between the average peak cutting force and the feed speed, the cutting depth is controlled by the cutting distance. The stress nephograms of the circular saw blade with various cutting depths are shown in Fig. 7. It is evident that the circular saw blade stress nephogram is closely related to the feed speed. The stress range of the circular saw blade expands with increasing feed speed. When the circular saw blade feed speed is $0.10 \mathrm{~m} / \mathrm{min}$, the circular saw blade stress is mainly concentrated in the centre of the circular saw blade matrix, and the area with apparent stress in the circular saw blade segments account for about $35.4 \%$ of the total. While the cutting speed of $0.20 \mathrm{~m} / \mathrm{min}$, the stress nephogram of the circular saw blade increases significantly compared with that of the feed speed of $0.10 \mathrm{~m} / \mathrm{min}$, and the stress concentration at the edge of the mounting hole of the circular saw blade matrix is more significant than that at the outer edge. There are apparent stress blocks, accounting for about $48.8 \%$ of the total. However, when the feed speed of $0.30 \mathrm{~m} /$ min, the circular saw blade stress increases obviously, the matrix stress nephogram expands the four holes position of the circular saw blade matrix, and the stress extends along with the position of the rotation direction. The number of stress blocks increases, accounting for about $50.0 \%$ of the total. With the increase of the feed speed, the water trough stress in the cutting area of the section that contacts the rock appears obvious, and the stress concentration appears at the tip of the section. The stress concentration appears at the connection position between the circular saw blade segments and the circular saw blade matrix.

In the circular saw blade cutting rock process, the rock stress nephograms are shown in Fig. 8. When the circular saw blade cuts into rock with constant cutting depth and rotation speed, it is clear that rock stress 


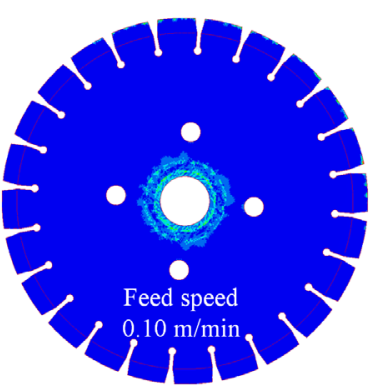

a)

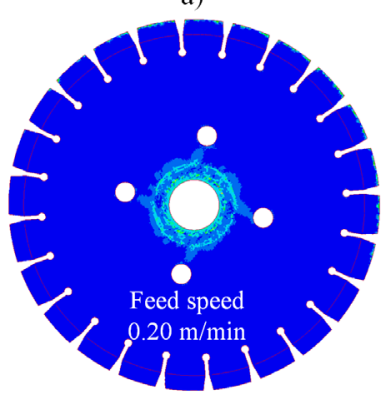

c)

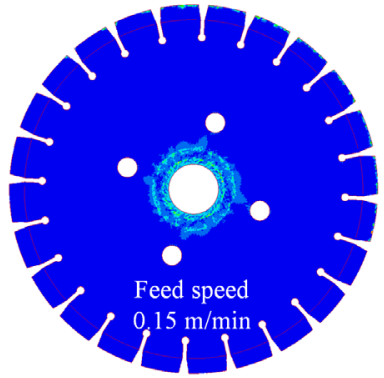

b)

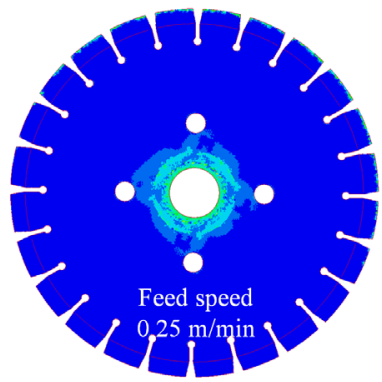

d)

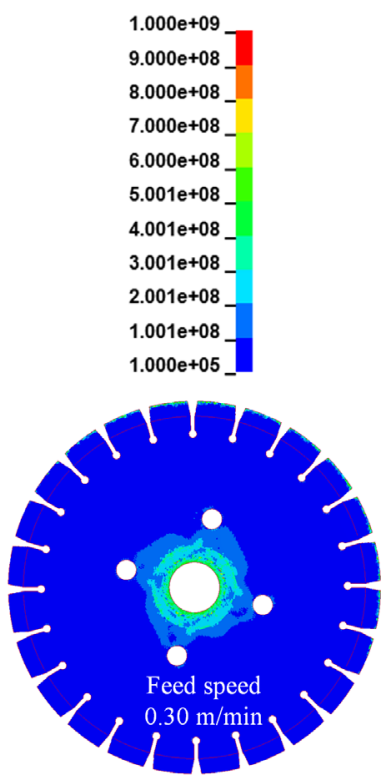

e)

Fig. 7. The circular saw blade stress nephogram with different feed speed

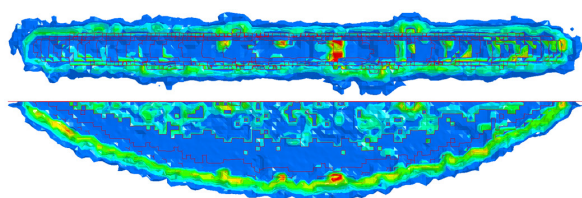

a)

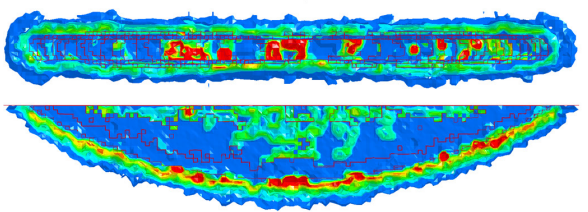

c)

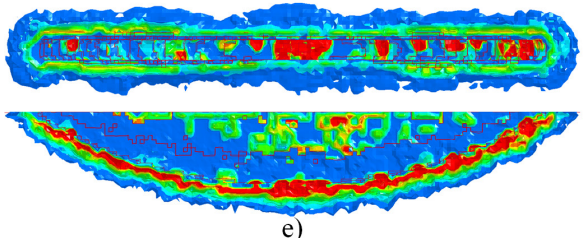

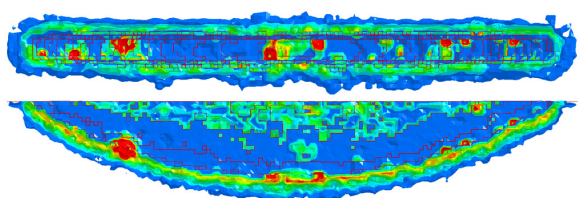

b)

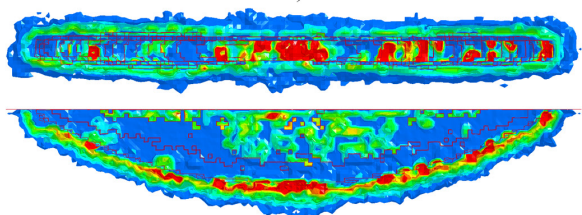

d)

Fig. 8. The rock stress nephogram with different feed speed; a) feed speed of $0.10 \mathrm{~m} / \mathrm{min}$, b) feed speed of $0.15 \mathrm{~m} / \mathrm{min}$, c) feed speed of $0.20 \mathrm{~m} / \mathrm{min}$, d) feed speed of $0.25 \mathrm{~m} / \mathrm{min}$, e) feed speed of $0.30 \mathrm{~m} / \mathrm{min}$

increases with the feed speed increasing. From the top view, the stress concentration area of rock is mainly distributed from the circular saw blade to the middle of the saw seam. The stress concentration gradually increases with the rising circular saw blade feed speed. The rock stress concentration area and the stress area width increase significantly with the circular saw blade feed speed rise. When the feed speed is 0.10 $\mathrm{m} / \mathrm{min}$, there are three obvious stress concentration points in the top view and four in the section view. However, when the feed speed increases to $0.30 \mathrm{~m} /$ min, 12 stress concentration points are in the top view.

Furthermore, in the rock stress profile, it can be observed that under the condition of a certain rotation speed the rock stress area increases significantly with the increased feed speed. When the feed speed is $0.10 \mathrm{~m} / \mathrm{min}$, there are few stress concentration areas on the action arc between the circular saw blade and 
rock. The stress concentration areas on the action arc between the circular saw blade and rock increase with the rise of the feed speed. When the circular saw blade feed speed rises $0.30 \mathrm{~m} / \mathrm{min}$, the action arc between the circular saw blade and rock forms a continuous stress region. Therefore, the circular saw blade stress increase with the increasing feed speed, and the maximum stress and stress range of the circular saw blade increases significantly.

The circular saw blade cuts the rock at different feed speeds, and the rock damage clouds are presented in Fig. 9. The circular saw blade cuts rock with constant rotation speed and different feed speeds, and the rock damage cloud area and degree are closely related to the feed speed. It can be observed from Fig. 9 that with the increase of feed speed, the width of rock damage cloud increase gradually, and the damage area at both ends of the damage cloud increases obviously. From the observation of the rock damage profile, it can be seen that the scope of rock damage rises significantly, and the damage area at the saw seam bottom increases gradually. With the increasing circular saw blade feed speed, the rock damage area increases and progressively connects with each other. Moreover, the rock damage at the cutting in area of the circular saw blade is more considerable than that

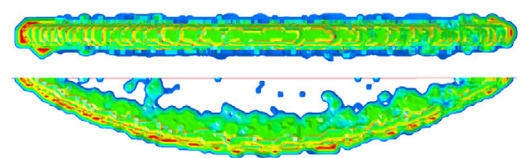

a)

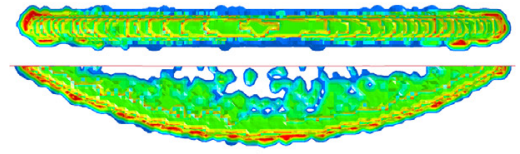

c)

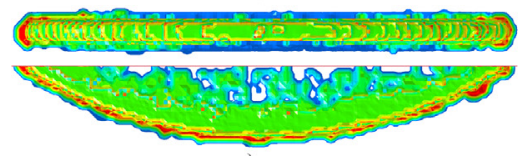

e)

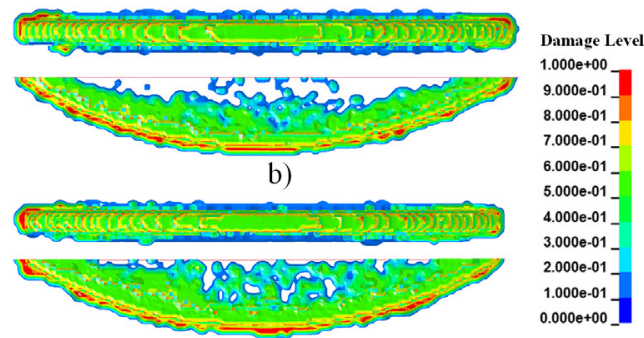

d)

Fig. 9. The rock damage cloud with different feed speed, a) feed speed of $0.10 \mathrm{~m} / \mathrm{min}$, b) feed speed of $0.15 \mathrm{~m} / \mathrm{min}$, c) feed speed of $0.20 \mathrm{~m} / \mathrm{min}$, d) feed speed of $0.25 \mathrm{~m} / \mathrm{min}$, and e) feed speed of $0.20 \mathrm{~m} / \mathrm{min}$
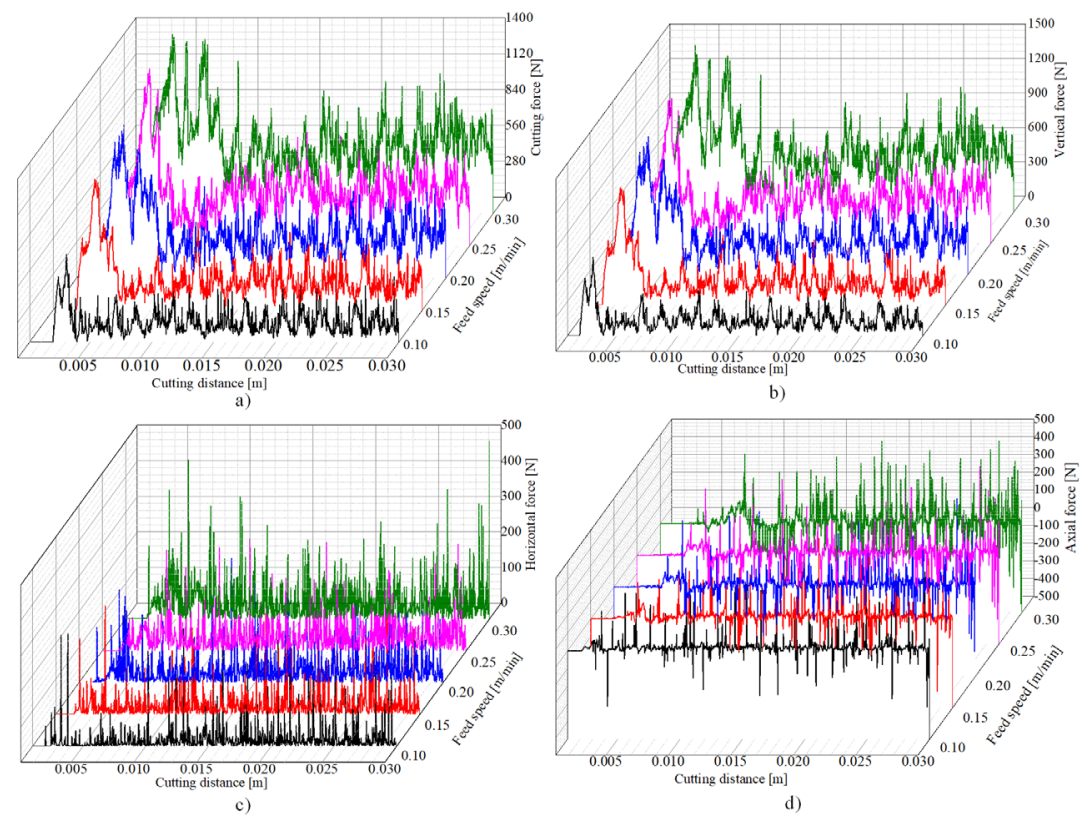

Fig. 10. The force curves of circular saw blade with different feed speeds; a) cutting force with different feed speeds, b) vertical force with different feed speeds, c) horizontal force with different feed speeds, $d$ ) axial force with different feed speeds 
at the cutting out area of the circular saw blade, and the damage range at the lowest part of the saw seam is the largest.

The curves of cutting force, vertical force, horizontal force, and axial force are shown in Fig. 10 , showing when the circular saw blade cuts rock with different feed speeds. The cutting force is closely related to the circular saw blade feed speed and increases sharply with increasing feed speed, as presented in Fig. 10a. The circular saw blade's horizontal cutting force and vertical cutting force increase obviously with increasing feed speed, as shown in Figs. 10b and c. The curves of cutting force, vertical force, horizontal force of the circular saw blade at different feed speeds show regularity. When the circular saw blade contacts the rock, the force curve increases significantly and decreases sharply, and fluctuates up and down around a stable value. The fluctuation of the circular saw blade cutting force and vertical force curve are similar. The curve of the circular saw blade axial force and the feed speed is shown in Fig. 10d. The axial force of different feed rates is basically same, and there is no obvious change between circular saw blade axial force and feed speed.

With the feed speed of the circular saw blade increasing, the thickness of the rock cutting by a circular saw blade increases while rotating a circle.
As a result, the interaction between the circular saw blade and rock increases, and the horizontal and vertical forces increase. However, because of the axial force in the compression of the broken rock between the circular saw blade and the rock wall of the saw seam, the axial force of the circular saw blade appears. Because the rock is quasi-brittle heterogeneous material, the rock fracture under the action of a circular saw blade has apparent randomness, so the force of rock cutting by the saw blade does not necessarily act on the plane of a circular saw blade.

The relation curve between the average peak force of the saw blade and the feed speed is presented in Fig. 11. The average peak force of the circular saw blade increases significantly. The variation trend of the average peak cutting force and the average vertical force is similar, increasing the feed speed. Meanwhile, the average peak horizontal force and axial force of the circular saw blade increase with the increasing feed speed. However, the increased amplitude is less than that of the cutting force and vertical force. The average peak cutting force and the average peak vertical force decrease with the increasing rotation speed, and the difference is significant, but the difference between the average peak horizontal force and average peak axial force is not obvious. The average peak axial force increases with the feed speed,
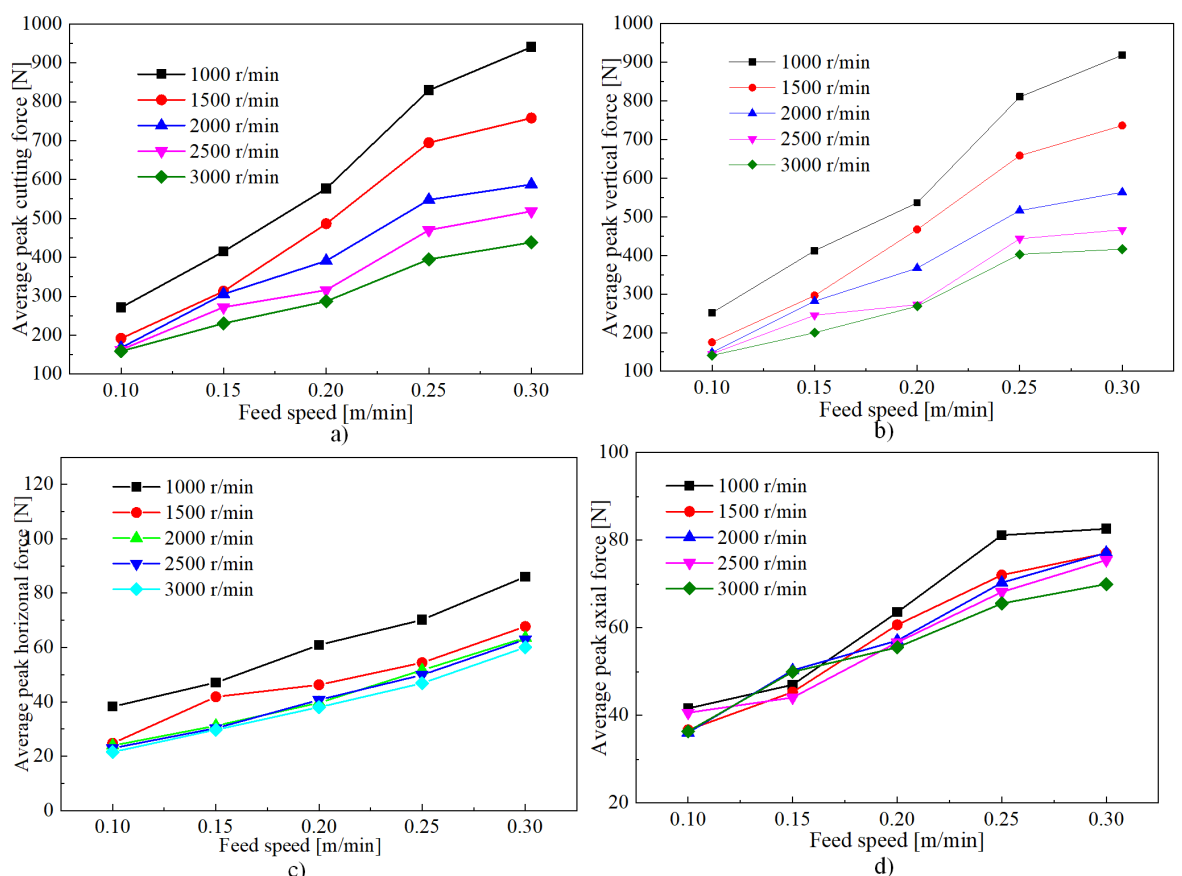

Fig. 11. The relationship curves between average peak force and feed speed; a) average peak cutting of different feed speeds, b) average peak vertical force of different feed speeds, c) average peak horizontal force of different feed speeds, d) average peak axial force of different feed speeds 
but the average peak axial force has little response to the rotation speed.

\subsection{The Influence of Rotation Speed on Circular Saw Blade Cutting Performance}

The circular saw blade cuts into the rock at the feed speed of $0.20 \mathrm{~m} / \mathrm{min}$ and the rotation speed of $1000 \mathrm{r} /$ $\mathrm{min}, 1500 \mathrm{r} / \mathrm{min}, 2000 \mathrm{r} / \mathrm{min}, 2500 \mathrm{r} / \mathrm{min}$, and $3000 \mathrm{r} /$ min. The circular saw blade stress nephogram is shown in Fig. 12. With the increasing rotation speed, there is a significant correlation between the stress cloud area and the peak value of the cloud and the rotation speed. With the increase of the circular saw blade rotation speed, the width of the annular stress area formed in the centre of the saw blade increases obviously. Furthermore, with the increasing rotation speed, the outward radiation area of the circular saw blade stress nephogram expands to the middle of the circular saw blade. The rotation speed significantly affects the

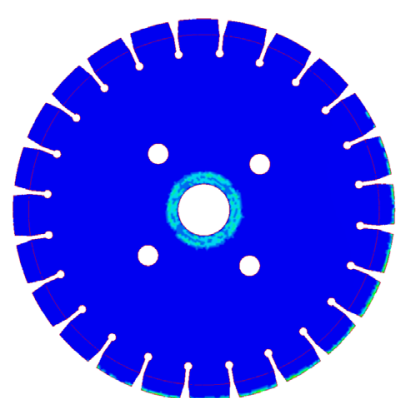

a)

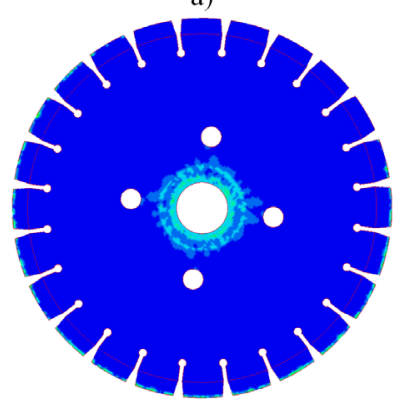

c)

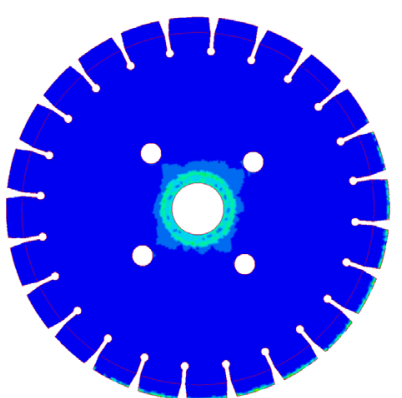

b)

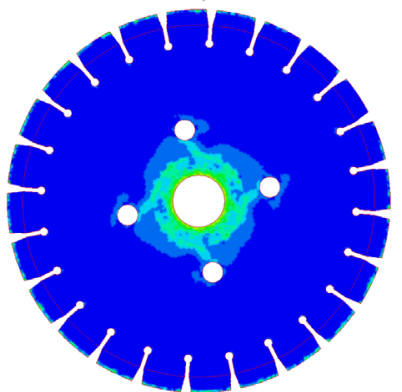

d)

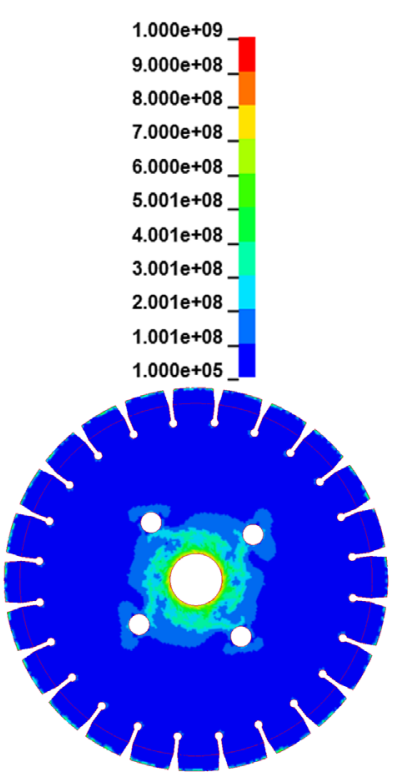

e)

Fig. 12. The circular saw blade stress nephogram with different rotation speeds; a) rotation speed $1000 \mathrm{r} / \mathrm{min}$, b) rotation speed $1500 \mathrm{r} / \mathrm{min}$, c) rotation speed $2000 \mathrm{r} / \mathrm{min}$, d) rotation speed $2500 \mathrm{r} / \mathrm{min}$, e) rotation speed $3000 \mathrm{r} / \mathrm{min}$

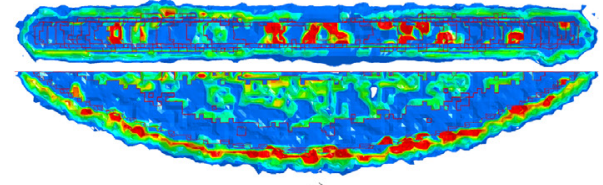

a)

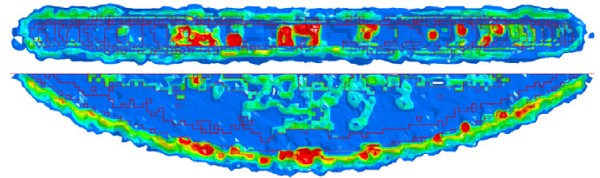

c)

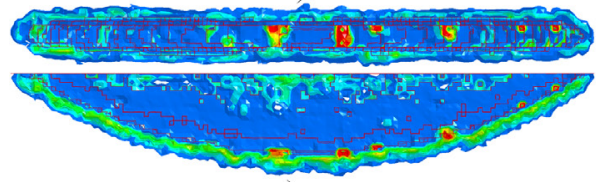

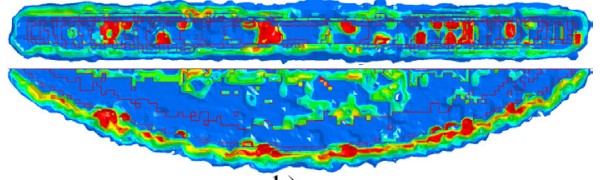

b)

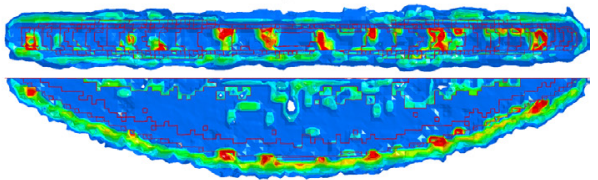

d)

e)

Fig. 13. The rock stress nephogram with different rotation speeds; a) rotation speed of $1000 \mathrm{r} / \mathrm{min}, \mathrm{b}$ ) rotation speed of $1500 \mathrm{r} / \mathrm{min}$, c) rotation speed of $2000 \mathrm{r} / \mathrm{min}$, d) rotation speed of $2500 \mathrm{r} / \mathrm{min}$, e) rotation speed of $3000 \mathrm{r} / \mathrm{min}$ 
stress of the circular saw blade, and the stress range of the saw blade segments increases. When the rotation speed of the saw blade is $1000 \mathrm{r} / \mathrm{min}$, the arc of the apparent stress of circular saw blade segments is about $43.75 \%$, and when the rotation speed of the saw blade is $3000 \mathrm{r} / \mathrm{min}$, the arc of the apparent stress cloud of the circular saw blade segment is about $100 \%$.

The rock stress cloud with the circular saw blade cutting rock at different rotational speeds is shown in Fig. 13. According to the rock stress nephogram, the top view and rock stress nephogram are closely related to the rotation speed. Under the circular saw blade action, the rock stress concentration area decreases significantly with the theorized rotation speed. From the top view of the rock stress nephogram, it can be concluded that the rock stress concentration area decreases obviously. Moreover, from the profile of the rock stress nephogram, it can be concluded that the stress concentration area of the rock decreases with the rotation speed increasing. With the increasing rotation speed, the rock stress decreases with the rise of the rotation speed.

The circular saw blade cuts into the rock at different rotation speeds, and the rock damage

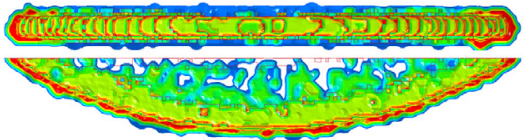

a)

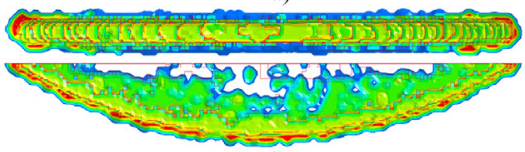

c)

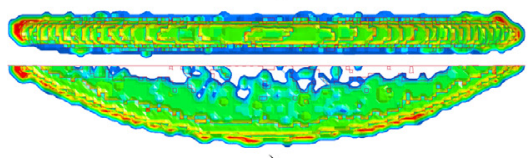

e)

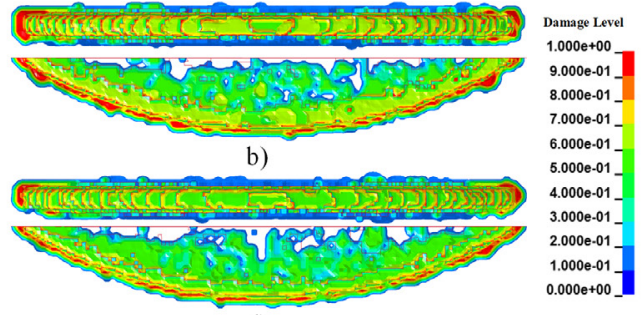

d)

Fig. 14. The rock damage nephogram with different rotation speeds; a) rotation speed of $1000 \mathrm{r} / \mathrm{min}, \mathrm{b}$ ) rotation speed of $1500 \mathrm{r} / \mathrm{min}$, c) rotation speed of $2000 \mathrm{r} / \mathrm{min}$, d) rotation speed of $2500 \mathrm{r} / \mathrm{min}$, e) rotation speed of $3000 \mathrm{r} / \mathrm{min}$
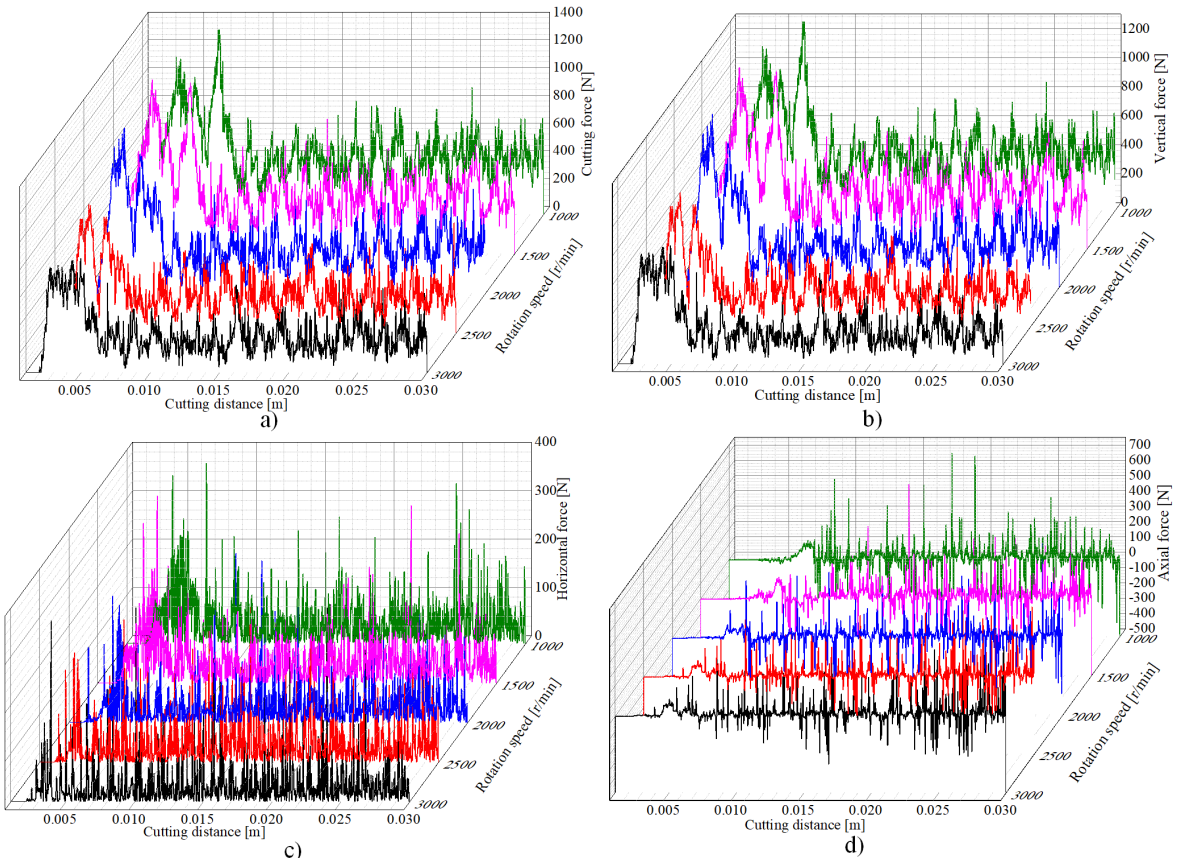

Fig. 15. The force curves of circular saw blade cutting rock with different rotation speeds; a) cutting force curve of different rotation speeds, b) vertical force curve of different rotation speeds, c) horizontal force curve of different rotation speeds, d) axial force curve of different rotation speeds 
nephograms are shown in Fig. 14. The circular saw blade rotation speed is constant, and the rock damage decreases with the rotation speed increase. From the top view of rock damage nephograms, it is apparent that rock damage gradually decreases, and the rock damage in the cut in and cut out area decreases with the rising rotation speed. In addition, the damage area of the rock saw seam bottom decreases with the increase of the circular saw blade rotation speed. While the rotation speed is $1000 \mathrm{r} / \mathrm{min}$, the damage area at the bottom of the saw seam is connected. When the rotation speed increases to $3000 \mathrm{r} / \mathrm{min}$, the damage area at the saw seam bottom decreases obviously, and the damage breaks off.

The curves of the cutting force, vertical force, horizontal force, and axial force of circular saw blade cutting rock at the cutting speed of $0.20 \mathrm{~m} / \mathrm{min}$, the rotation speed of $1000 \mathrm{r} / \mathrm{min}, 1500 \mathrm{r} / \mathrm{min}, 2000 \mathrm{r} /$ $\mathrm{min}, 2500 \mathrm{r} / \mathrm{min}$, and $3000 \mathrm{r} / \mathrm{min}$ are shown in Fig. 15. The results show that cutting force, vertical force, horizontal force, and axial force of circular saw blade with different rotation speeds are similar to the distance curve. There is a significant sudden increase when the circular saw blade contacts the circular saw blade rock. There is a negative correlation between the force and rotation speed. After the cutting force returned to stable fluctuation, the circular saw blade's cutting force and vertical force were positively correlated with the circular saw blade cutting depth. The changing trend of fluctuation increases. The fluctuation of the horizontal force curve of the circular saw blade decreases, and the horizontal force increases sharply when the circular saw blade contacts the rock. It returns to stability in a short time. Compared with the cutting force, vertical force, and horizontal force, the axial force appears later. The axial force fluctuates up and down around the stable value, and the fluctuation amplitude decreases with the increases of circular saw blade rotation speed.

The circular saw blade cut into rock vertically with the constant feed speed and rotation speed. At the moment of the circular saw blade contacting rock, the cutting force, horizontal force, vertical force curves increase sharply, owing to the impact of the circular saw blade. However, the relationship between peak cutting force and the rotation speed is significant, and rotation speed substantially affects the effects of the circular saw blade. The circular saw blade cuts rock at a constant feed speed. The rotation speed directly affects the cutting amount of circular saw blades in one cycle and then affects the cutting and transverse forces. When the rotation speed is low, the cutting amount of the saw blade for a cycle increases, but the cutting force, vertical force, and horizontal force

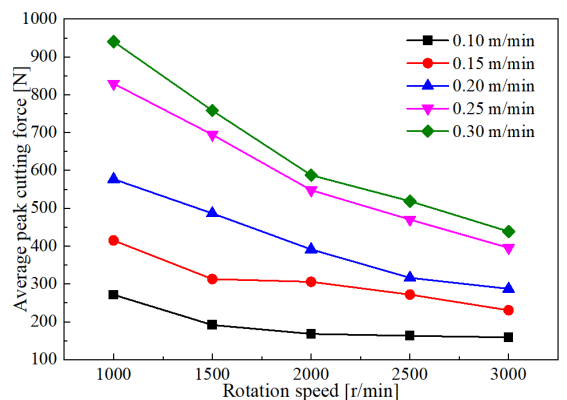

a)

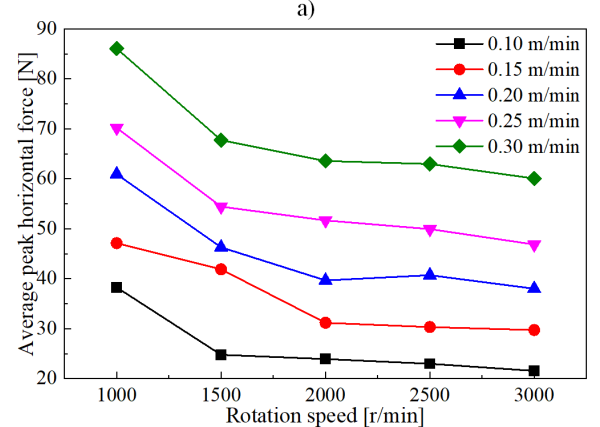

c)
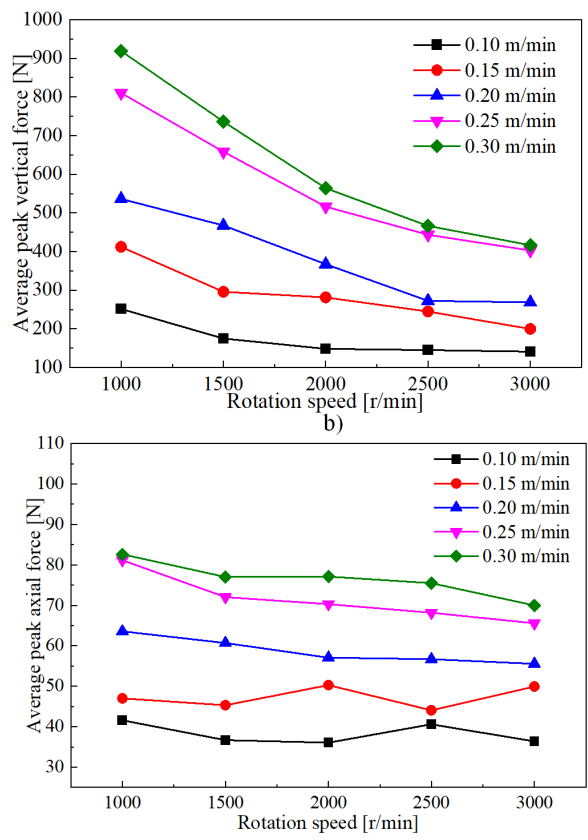

d)

Fig. 16. The average peak force with different rotation speeds; a) average peak cutting force of different rotation speeds, b) average peak vertical force of different rotation speeds, c) average peak horizontal force of different speeds,

d) average peak axial force of different rotation speeds 
increase. The rotation speed directly affects the discharge speed of rock debris, so the axial force of the circular saw blade is affected by the rotation speed of the saw blade and decreases with the increase of the rotation speed.

The average peak cutting force, vertical, horizontal, and axial force curves with different feed speeds are plotted in Fig. 16. The average peak cutting force, vertical, horizontal, and axial force correlate closely with rotation speed. With increasing rotation speed, the cutting force, vertical force, horizontal force, vertical force, and axial force decreases, but the reduced amplitude decreases. The average peak cutting force, vertical force, horizontal force, and axial force of circular saw blade respond rapidly to the speed of the circular saw blade. It is apparent that the cutting force and vertical force are significantly affected by the rotation speed of the circular saw blade, and the variation trend is similar. The horizontal force of the circular saw blade decreases slightly with the increase of the rotation speed, which is slightly less than the cutting force and vertical force of the circular saw blade. However, the rotation speed curves of the average peak cutting force, vertical force, horizontal force, and axial force of the circular saw blade under different feed speeds do not cross.

\subsection{The Double Circular Saw Blades Distance Influence on Cutting Performance}

The double circular saw blade cuts vertically with a feed speed of $0.20 \mathrm{~m} / \mathrm{min}$, a rotation speed of 2000 $\mathrm{r} / \mathrm{min}$, and a distance between double circular saw blades of $30 \mathrm{~mm}$. The curves of cutting force, vertical force, horizontal force, axial force, and cutting distance of single and double circular saw blades are shown in Fig. 17. Comparing the cutting force of the single circular saw blade and double circular saw blades, it can be seen that the cutting force, vertical force, horizontal force, and axial force of the double circular saw blade are smaller than that of the single circular saw blade. When the circular saw blade contacts the rock, the impact action of the circular saw blade results in a sharp increase in the force position curve. After the stable cutting, the cutting force curve restores to the stable value. The cutting force, vertical force, horizontal force fluctuate up and down around the stable value, and show an upward trend, because the superposition effect of the cutting force of the double circular saw blade is smaller than that of the single circular saw blade, and the fluctuation range of the cutting force, vertical force and horizontal force of the double circular saw blade is smaller than that of the single circular saw blade. Comparing the curves of the axial force curve of the single circular

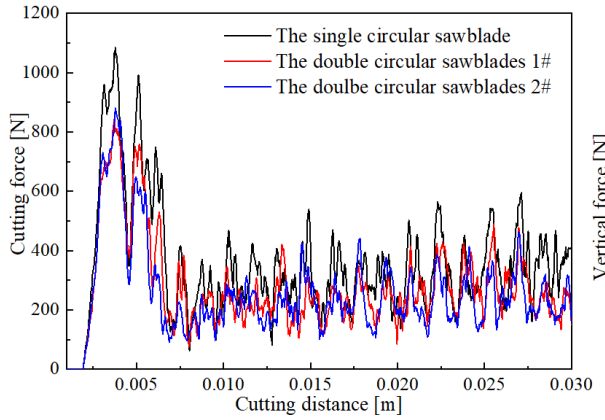

a)

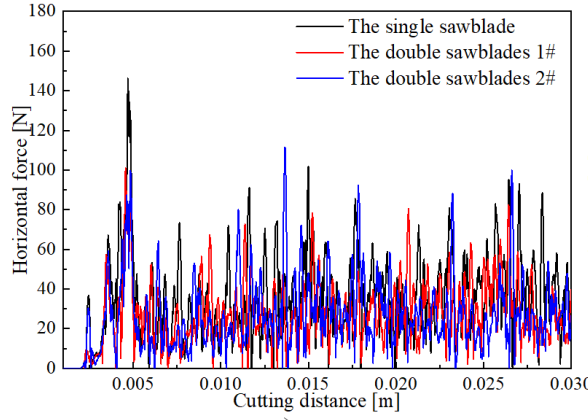

c)

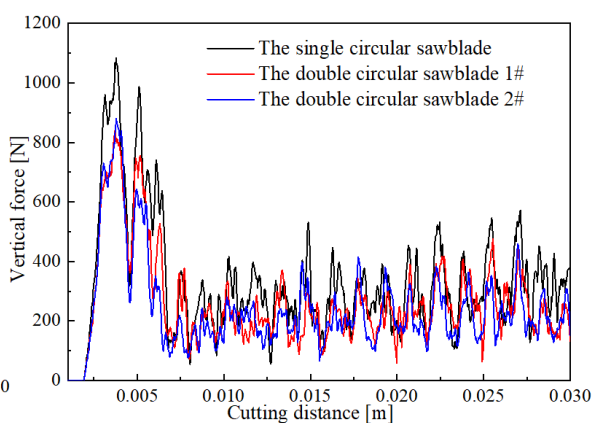

b)

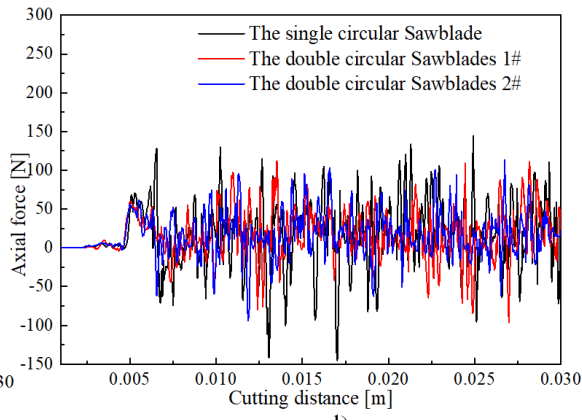

d)

Fig. 17. The force curves of single circular saw blade and double circular saw blades 

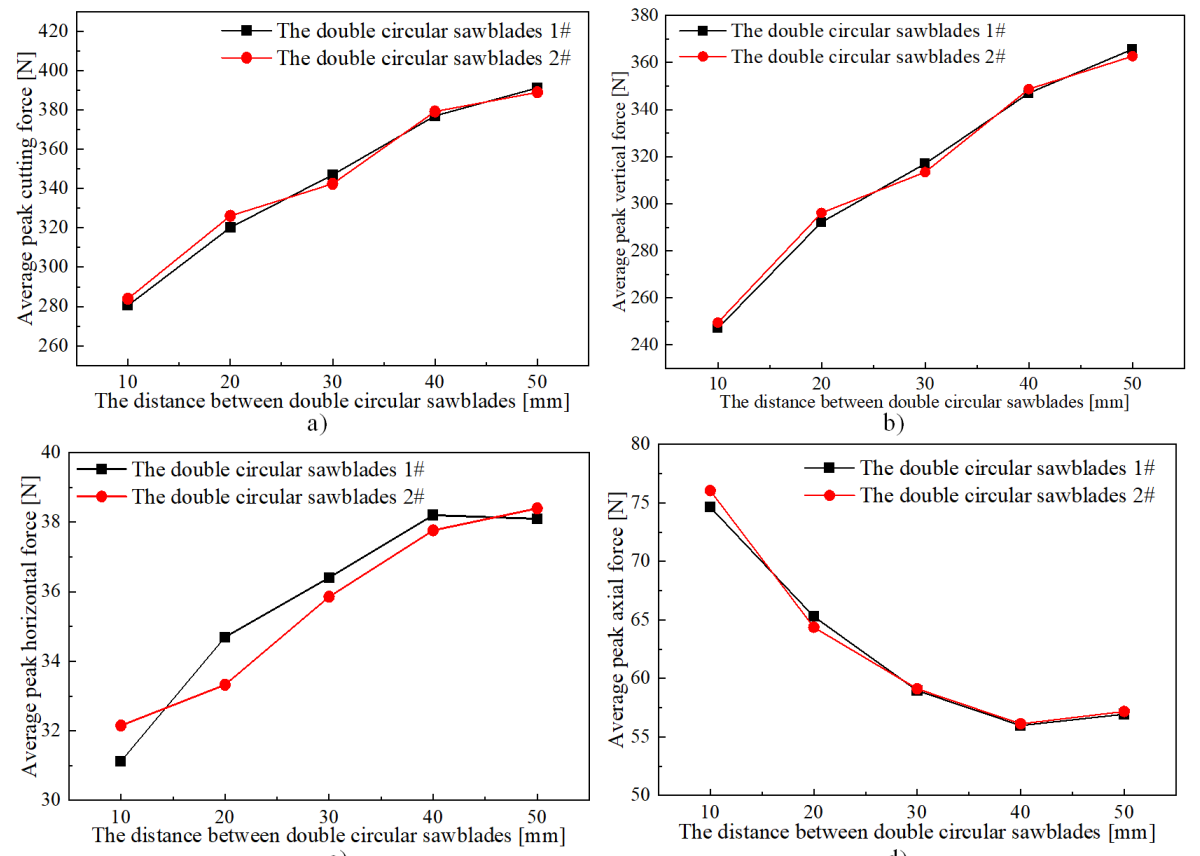

c)

d)

Fig. 18. The average peak force of the double circular saw blade with different distances between double circular saw blades; a) the average peak cutting force of different distance between double circular sawblades, b) the average peak vertical force of different distance between double circular sawblades, c) the average peak horizontal force of different distance between double circular sawblades, d) the average peak axial force of different distance between double circular sawblades

saw blade and the double circular saw blade, the axial force fluctuation of the axial force curve of the double circular saw blade is smaller than that of the single circular saw blade. Therefore, with the same cutting parameters, the double circular saw blade cutting rock is conductive to reducing the impact load and can effectively improve the service life of the circular saw blade.

The results show that the circular saw blade cutting rock with the rotation speed of $2000 \mathrm{r} / \mathrm{min}$, the feed speed of $0.20 \mathrm{~m} / \mathrm{min}$, and the distance between the double circular saw blade is $10 \mathrm{~mm}, 20 \mathrm{~mm}, 30 \mathrm{~mm}$, $40 \mathrm{~mm}$, and $50 \mathrm{~mm}$, respectively. The curves of the average peak cutting force, vertical force, horizontal force, and axial force of the double circular saw blade are shown in Fig. 18. With the increase of the double circular saw blades, the average peak cutting force, vertical force, horizontal force gradually increase and tend to be stable. The average peak cutting force decreases gradually and tends to be stable. This is seen by comparing the cutting force, vertical force, horizontal force, and axial force of the double circular saw blade. When the distance of the double circular saw blades are small, the average peak cutting force, vertical force, horizontal force, and axial force of the circular saw blade are significantly smaller than that of the single circular saw blade. However, the axial force of the double circular saw blade is more significant than that of the single circular saw blade. With the distance between the double circular saw blade increase, the average peak cutting force, vertical force, horizontal force, and the axial force of the double circular saw blade are close to that of the single saw blade.

When the double circular saw blades cut into the rock vertically, the double circular saw blades spacing significantly affects the stress superposition of the double circular saw blades. The stress distribution of the single circular saw blade cutting rock presents a large arc, while the double saw blades cut rock with different distances between the double circular saw blades. The stress superposition of rock is closely related to the double circular saw blade spacing. Owing to the superposition of the stress acting on the rock, the average peak cutting force, vertical force, and horizontal force are closely related to the distance between the double circular saw blades. However, due to the superimposed stress of the double saw blade, the axial force of the saw blade is negatively correlated with the distance between the double circular saw blades. When the distance between the two saw blades is small, the axial force of the rock cutting by the 
double circular saw blades is significantly greater than that cut by the single circular saw blade. When the distance between double circular saw blades increases to a certain distance, the average peak cutting force, vertical force, horizontal force, and axial force are similar to those of the single circular saw blade.

\section{CONCLUSION}

The flexible circular saw blade cutting into rock process with different feed speeds and rotation speeds was investigated based on the ANSYS/LS-DYNA. The cutting parameters of the circular saw blade influence the stress distribution of flexible circular saw blade and rock, as well as the cutting force, vertical force, horizontal force, and axial force. The conclusions are as follows:

(1) The feasibility of the numerical simulation is verified by uniaxial compression test and uniaxial compression numerical simulation to correct the accuracy of the rock cutting model of the flexible circular saw blade.

(2) The results indicated that the stress distribution range of a flexible circular saw blade increases with the increase of feed speed and rotation speed. The stress distribution of circular saw blade segment and circular saw blade has a significant correlation with cutting parameters.

(3) The cutting force of the circular saw blade is closely related to the cutting parameters of the saw blade, which decreases with the increase of the rotation speed of the saw blade and increases with the growth of the feed speed.

(4) The results show that the double saw blade's cutting force, vertical force, and horizontal force are smaller than that of the single saw blade, but the axial force is more significant than that of the single saw blade.

(5) The cutting force, horizontal force, and vertical force of double saw blade increase with the increase of saw blade spacing, but the axial force of the saw blade decreases with the increase of saw blade spacing.

In the future investigation, I will study the circular saw blade cutting different kinds of hard rocks and research the rock parameters effects on the circular saw blade cutting performance and rock fracture.

\section{ACKNOWLEDGEMENTS}

This work was supported by the projects of the Key Research and Development project of China (Grant No. 2017YFC0603000), Shandong Provincial Key
Research and Development Project (2019SDZY01), and the Natural Science Foundation of Shandong Province (Grant No. ZR2019BEE069).

\section{REFERENCES}

[1] Aydin, G., Karakurt, l., Aydiner, K. (2013). Development of predictive models for the specific energy of circular diamond saw blades in the sawing of granitic rocks. Rock Mechanics Rock Engineering, vol. 46, p. 767-783, Dol:10.1007/s00603012-0290-6.

[2] Aydin, G., Karakurt, I., Hamzacebi, C. (2015). Performance prediction of diamond saw blades using artificial neural network and regression analysis. Arabian Journal for Science and Engineering, vol. 40, p. 2003-2012, D0l:10.1007/ s13369-015-1589-x.

[3] Aydin, G., Karakurt, I., Aydiner, K. (2013). Wear performance of saw blades in processing of granitic rocks and development of models for wear estimation. Rock Mechanics and Rock Engineering, vol. 46, p. 1559-1575, Dol:10.1007/s00603013-0382-y.

[4] Goktan, R.M., Yilmaz, N.G. (2017). Diamond tool specific wear rate assessment in granite machining by means of Knoop micro-hardness and process parameters. Rock Mechanics and Rock Engineering, vol. 50, p. 2327-2343, Dol:10.1007/ s00603-017-1240-0.

[5] Li, Y., Huang, H., Shen, J.Y., Xu, X.P., Gao, Y.S. (2002). Costeffective machining of granite by reducing tribological interactions. Journal of Materials Processing Technology, vol. 129, no. 1-3, p. 389-394, Dol:10.1016/S09240136(02)00699-4.

[6] Yilmaz, N.G. (2016). Size analysis of the chips generated during abrasive machining of granite in relation to productivity and efficiency parameters. Particulate Science and Technology, vol. 34, no. 5, p. 593-601, Dol:10.1080/027263 51.2015.1096872.

[7] Ataei, M., Mikaeil, R., Hoseinie, S.H., Hosseini, S.M. (2012). Fuzzy analytical hierarchy process approach for ranking the sawability of carbonate rock. International Journal of Rock Mechanics and Mining Sciences, vol. 50, p. 83-93, D0I:10.1016/j.jijmms.2011.12.002.

[8] Atici, U., Ersoy, A. (2009). Correlation of specific energy of cutting saws and drilling bits with rock brittleness and destruction energy. Journal of Materials Processing Technology, vol. 209, no. 9, p. 2602-2612, D0l:10.1016/j. jmatprotec.2008.06.004.

[9] Aslantas, K., Ozbek, O., Ucun, I., Buyuksagis, I.S. (2009). Investigation of the effect of axial cutting force on circular diamond saw blade used in marble cutting process. Material and Manufacturing Processes, vol. 24, no. 12, p. 1423-1430, DOl:10.1080/10426910903344039.

[10] Ersoy, A., Atici, U. (2004). Performance characteristics of circular diamond saws in cutting different types of rocks. Diamond and Related Materials, vol. 13, no. 1, p. 22-37, D0I:10.1016/j.diamond.2003.08.016.

[11] Tumac, D. (2015). Predicting the performance of large diameter circular saws based on Schmidt hammer and other properties for some Turkish carbonate rocks. International 
Journal of Rock Mechanics and Mining Sciences, vol. 75, p. 159-168, D0l:10.1016/j.jijmms.2015.01.015.

[12] Tumac D. (2016). Artificial neural network application to predict the sawability performance of large diameter circular saws. Measurement, vol. 80, p. 12-20, D0l:10.1016/j. measurement.2015. 11.025.

[13] Mikaeil, R., Haghshenas, S.S., Haghshenas, S.S., Ataei M. (2016). Performance prediction of circular saw machine using imperialist competitive algorithm and fuzzy clustering technique. Neural Computing and Applications, vol. 29, p. 283-292, D0I:10.1007/s00521-016-2557-4.

[14] Yilmaz, N.G. (2013). Process efficiency comparison of a sandwich-core saw blade and a conventional saw blade used in stone-machining. Journal of Cleaner Production, vol. 47, p. 26-31, D0I:10.1016/j.jclepro.2013.01.042.

[15] Tonshoff, H.K., Hilmann-Apmann, H., Asche, J. (2002). Diamond tools in stone and civil engineering industry: cutting principles, wear and applications. Diamond and Related Materials, vol. 11, p. 736-741, D0l:10.4028/www.scientific. net/KEM.250.103.

[16] Xu, X., Li, Y., Yu, Y. (2003). Force ratio in the circular sawing of granites with a diamond segmented blade. Journal of Materials Processing Technology, vol. 139, no. 1-3, p. 281285, D0I:10.1016/S0924-0136(03)00236-X.

[17] Karakurt, I., Aydin, G., Aydiner, K. (2013). Experimental and statistical analysis of cutting force acting on diamond sawblade in sawing of granitic rocks. Proceedings of the Institution of Mechanical Engineers, Part B: Journal of Engineering Manufacture, vol. 227, no. 2, p. 286-300, DOI:10.1177/0954405412460971.

[18] Buyuksagis, I.S., Goktan, R.M. (2005). Investigation of marble machining performance using an instrumented block-cutter. Journal of Materials Processing Technology, vol. 169, no. 2, p. 258-262, Dol:10.1016/j.jmatprotec.2005.03.014.

[19] Jiang, K., Gao, K., Wan, L. (2020). Effect of gangue distributions on cutting force and specific energy in coal cutting. Strojniški vestnik - Journal of Mechanical Engineering, vol. 66, no. 3, p. 203-212, D0l:10.5545/sv-jme.2019.6461.

[20] Agarwal, S., Rao, P.V. (2008). Experimental investigation of surface/subsurface damage formation and material removal mechanisms in SiC grinding. International Journal of Machine Tools and Manufacture, vol. 48, no. 6, p. 698-710, DOl:10.1016/j.ijmachtools.2007.10.013.
[21] Burek, J., Plodzien, M., Zylka, L., Sulkowicz, P. (2019). Highperformance end milling of aluminum alloy: Influence of different serrated cutting edge tool shapes on the cutting force. Advances in Production Engineering \& Management, vol. 14, no. 4, p. 494-506, D0l:10.14743/apem2019.4.344.

[22] Lu, Z., Zeng, Q., Wang, Z., Li, X., Gao, K. (2019). Experimental and numerical studies on rock cutting with saw blade and conical pick combined cutting method. Mathematical Problems in Engineering, vol. 2019, art. ID 5046873, DOI:10.1155/2019/5046873.

[23] Zeng, Q., Wang, Z., Lu, Z., Wan, L., Zhang, X. (2021). Numerical simulation of the influence of the distance between the diamond sawblade and free surface on cutting performance. Shock and Vibration, vol. 2021, art. ID 2958204, DOI:10.1155/2021/2958204.

[24] Hoang, H.T., Nguyen, N.T., Tran, D.Q., Nguyen, V.T. (2019). cutting forces and surface roughness in face-milling of SKD61 hard steel. Strojniški vestnik - Journal of Mechanical Engineering, vol. 65, no. 6, p. 375-38, D0l:10.5545/svjme.2019.6057.

[25] Liu, J., Sun, J., Zaman, U.K.U., Chen, W. (2020). Influence of wear and tool geometry on the chatter, cutting force, and surface integrity of TB6 titanium alloy with solid carbide cutters of different geometry. Strojniški vestnik - Journal of Mechanical Engineering, vol. 66, no. 12, p. 709-723, DOI:10.5545/sv-jme.2020.6714.

[26] Fernando, P.K.S.C., Pei, Z.J., Zhang, M.. (2020). Mechanistic cutting force model for rotary ultrasonic machining of rocks. International Journal of Advanced Manufacturing Technology, vol. 109, p. 109-128, D0l:10.1007/s00170-020-05624-z.

[27] Zuperl, U., Cus, F., Zawada-Tomkiewicz, A., Stepien, K. (2020). Neuro-mechanistic model for cutting force prediction in helical end milling of metal materials layered in multiple directions. Advances in Production Engineering and Management, vol. 15, no. 1, p. 5-17, DOl:10.14743/apem2020.1.345.

[28] Peng, Z.H., Fang, C.F. (2019). Study on force distribution and its location in granite sawing. IOP Conference Series: Materials Science and Engineering, vol. 504, art. ID 012112, DOl:10.1088/1757-899X/504/1/012112.

[29] Liu, S.F., Lu, S.F., Wan, Z.J., Cheng, J.Y. (2019). Investigation of the influence mechanism of rock damage on rock fragmentation and cutting performance by the discrete element method. Royal Society Open Science, vol. 6, art. ID 190116, DOI:10.1098/rsos.190116. 